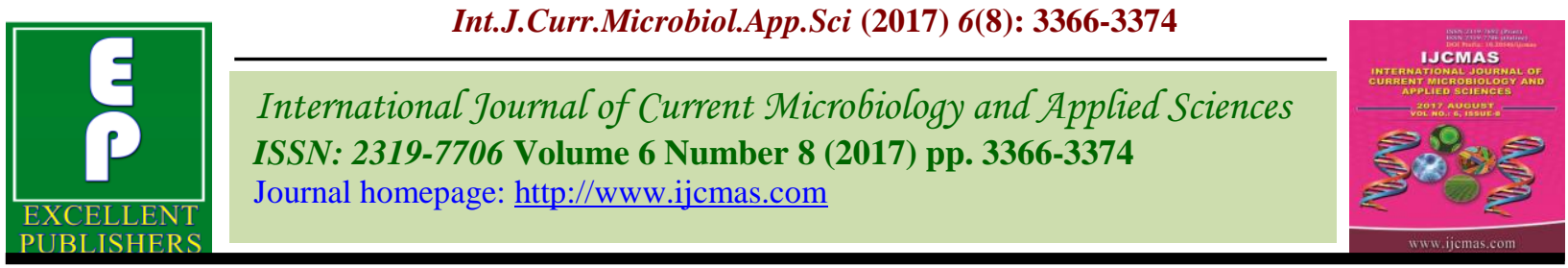

Original Research Article

https://doi.org/10.20546/ijcmas.2017.608.402

\title{
Scientific Approaches of Gum Tapping in Gum Karaya (Sterculia urens Roxb.) for High Gum Production
}

\author{
Vidya Bhushan Kuruwanshi*, Pratibha Katiyar and Shabnam Khan
}

Department of Plant Physiology, Agricultural Biochemistry, Medicinal and Aromatic plants, Indira Gandhi Krishi Vishwavidyalaya, Raipur -492 012, Chhattisgarh, India

*Corresponding author

\section{Keywords \\ Sterculia urens, Ethephon, IAA, Gum tapping, Gum yield. \\ Article Info \\ Accepted: \\ 26 June 2017 \\ Available Online: \\ 10 August 2017}

\section{A B S T R A C T}

Gum is natural biopolymers and formed via process of gummosis due to biotic and abiotic stresses i.e. injury, infection, drought, heat, high temperature, asby product of metabolic pathway and cannot re-enter in the system. Gum karaya (Sterculia urens Roxb.) is a dry deciduous tree belonging to the family Sterculiaceae distributed throughout India and Chhattisgarh. Karaya gum is the dried exudate obtained from trees of Sterculia species. Karaya gum is predominately used for many industries such as petroleum and gas, textiles, paper and pulp, pharmaceuticals, medicine and several other products. The commercial tapping of karaya is done by blazing, peeling, or by making deep cuts at the base of the bole using an axe or a cycle. These methods often lead to the death of the tapped trees. On account of crude tapping methods and over exploitation the population of karaya trees has markedly declined. The harvesting methods currently used are traditional and injurious due to which often obtained inferior quality of products. Hence, the study was undertaken in ICAR Network Project to develop the scientific tapping technique for sustainable harvesting in major gum producing tree of Chhattisgarh state to enhance the livelihood of the rural areas as well as to protect the plant and generate the revenue of the government. The various chemical methods are used for tapping purpose. Chemical tapping method using ethephon and IAA injected by battery operated drill machine. However, temperature and relative humidity also play significant role in gum exudation. The ethephon @ $3.9 \%$ in $4 \mathrm{ml}$ in two consecutive doses in 45-60 days intervals at high temperature in month of April to June was found significantly effective for maximum gum production during both the year 2015 and 2016. The physiochemical properties of exudated gum were investigated and gum was found to be mild acidic, least soluble in cold water but absorb water and swell, soluble in hot water but insoluble in organic solvent.

\section{Introduction}

Gums and resins occupy a prime place among Non-Wood Forest Produce (NWFP/NTFP) and are known to mankind since time immemorial. Gum trees are economically important and found in tropical moist and dry deciduous forests, produce a significant quantity of gum, which are widely used as industrial, food and medicinal purposes in India (Bhattacharya, 2012). Gums are metabolic by-products of plant tissues either in normal course or often as a result of disease or injury to the bark or wood of certain plants. The gum exudes from trees and shrubs in tear-like, striated nodules or amorphous lumps. It dries in contact with air and sunlight and forms hard, glass like lumps. Gum production increases at high temperature and limited moisture. India is a rich center of plant 
biodiversity having more than 15,000 plant species including about 120 gum yielding plants. India produces annually about 2,81,000 tons of gum (Anonymous, 2013).

Karaya gum is the dried exudate from the tree Sterculia urens. It is also known as Thapsi Gum, Gum Kadaya, Kullo, Karei, Kandol, Katilo, Gulu, Katera, Katiera in the trade (Plate.1a). Sterculia urens is the source of karaya gum which is an important raw material in the textile cosmetic, food, pharmaceutical and other industries. Gum karaya is collected as exudates from the natural wounds or from the cuts made artificially (tapping) on the stem and the branches of Sterculia urens. (Sao, 2012) The gum ducts normally occur in the pith and cortex of young stem of Sterculia urens.

Time course experiments involving mechanical injury to both young and old stems indicate that gum ducts are also formed in the xylem within 30-40 minutes. These ducts, called as traumatic ducts, are formed as a result of breakdown of xylem cells. A traumatic duct shows an irregular lumen without any distinct epithelial cells. Histochemical test reveals that the nature of the gum produced in these ducts is similar to that in the normal ducts. (Setia, 1984).

The commercial tapping of Gum karaya is done by blazing, peeling, or by making deep cuts at the base of the bole using an axe or a sickle (Plate.1b). These methods often lead to the death of the tapped trees. Gum karaya is vital for tribal economy and its trade value is substantial, there is a pressing need to develop a scientific and sustainable tapping method to increase the yield and ensure the survival of the tapped trees. A simple and safe technique of tapping with substantial increase in the yield is developed using ethephon to enhance gum yield and wound healing (Gupta et.al. 2012).
Traditionally trees are tapped by blazing, stripping of the bark or making deep cuts in the base of the tree with axe. Trees are tapped to increase gum yield by making incisions in the bark or treating with stress hormone ethylene or ethylene-releasing compounds such as ethephon (2-chloroethylphosphonic acid). The idea to use ethephon as gum inducer came from the thought that if ethylene is supplied artificially to the tree via the application of ethephon, the developmental response to stress could be accelerated, and, consequently, more gum exudates could be obtained. Ethephon can mimic the effect of water stress, as it releases the stress hormone ethylene in plant tissues.

The gum yield increase with increase in concentration of ethephon. Indole-3-acetic acid (IAA, 3-IAA) is the most common, naturally-occurring, plant hormone of the auxin class. It is the best known of the auxins, and has been the subject of extensive studies by plant physiologists (Siman and Petrasek, 2011).

An Application of Indole 3-acetic acid (IAA) increase the number of gum ducts in Sterculia urens (Setia and Shah, 1977a) However, gum tapping using scientific methods of gum exudation not only increase the life span of the tree but also yields good quality gum of high International value (Gupta et al., 2012).

\section{Materials and Methods}

An investigation was carried out at former Central Government Forest Division, Biladi at Tilda block of Raipur (Chhattisgarh) during year 2015 and 2016. The experiment was laid out in Randomized Block Design with three replication and six treatment i.e. $\mathrm{T}_{1}$ control (distilled water), different Ethephon concentration $\left(\mathrm{T}_{2} 2.34 \%, \mathrm{~T}_{3} 3.12 \%, \mathrm{~T}_{4} 3.9 \%\right)$ and IAA ( $\left.\mathrm{T}_{5} 400 \mathrm{ppm}, \mathrm{T}_{6} 800 \mathrm{ppm}\right)$ for potential gum production in Sterculia urens Roxb. 


\section{Gum tapping method}

The chemical gum tapping of selected trees was initiated using different doses of gum enhancer ethephon (2-chloro-ethylphosphonic acid) (trade name Ethrel) having 39\%, Indole acetic acid (IAA @ 400 and $800 \mathrm{ppm}$ ) in the tree trunk by battery operated drill machine to induce gummosis. The whole treatments were made through a syringe of 10 $\mathrm{ml}$ volume. The $4 \mathrm{ml}$ gum enhancer was injected twice during the whole period of tapping. First treatment injected in March and second in the month of May. Two slanted hole of about $6 \mathrm{~mm}$ diameter with 1" deep was made on at least one meter tree girth and confined one feet above the collar of the tree with the help of battery operated drill machine. After that, $4 \mathrm{ml}(2 \mathrm{ml}$ each hole $)$ dose of ethephon and IAA gum enhancer were applied/injected in the hole with the help of syringe and immediately the hole was covered (patched up) by moistened clay. It is observed that the tree starts exudating gum tears after 7-10 days of treatment (Plate.1c). The exudates gum was picked by hand as large stalactic mass. The distilled water used as control was injected $4 \mathrm{ml}$ ( $2 \mathrm{ml}$ each hole) in the hole of trees. The rate of gum exudation was measured by application of chemical treatment and collecting the gum at different time intervals in a month. It was collected after one week of the commencement of treatment. It was calculated by weighing the exudated gum and divided it by time. The quantity of gum exudation was measured by collecting the gum at different time interval in a month and adds them. The yield data per year obtained was compared to check variation in gum exudates per month on the basis of weight.

\section{Physiochemical analysis}

The physiochemical analysis of gum samples study was done in Department of Plant
Physiology, Agricultural Biochemistry, Medicinal and Aromatic plants, Indira Gandhi Krishi Vishwavidyalaya, Raipur (C.G.) laboratory. Each analysis was repeated three times and values reported in respect of the gum samples are actually the average of three replications.

\section{Determination of $\mathrm{pH}$}

The sample powder was thoroughly mixed and $1 \mathrm{~g}$ and was dissolved in $100 \mathrm{ml}$ of hot distilled water. The mixture was allowed to stand for $5 \mathrm{~min}$ at room temperature before the $\mathrm{pH}$ and temperature was recorded using a pre-calibrated $\mathrm{pH}$ meter (Ameh, 2012).

\section{Determination of solubility}

The solubility of the gum was determined in cold and hot distilled water, acetone, and ethanol. $1.0 \mathrm{~g}$ sample of the gum was added to $50 \mathrm{~mL}$ of each of the above mentioned solvents and left overnight. $25 \mathrm{~mL}$ of the clear supernatants were taken in small pre weighted evaporating dishes and heated to dryness over a digital thermostatic water bath. The weights of the residue with reference to the volume of the solutions were determined using a digital top loading balance and expressed as the percentage solubility of the gums in the solvents (Eddy et al., 2012).

\section{Determination of protein}

Crude protein content of the gum was determined using the Kjeldahl method with the nitrogen content being multiplied by a factor of 6.25 (Rodriguez et al., 2004).

\section{Results and Discussion}

The data pertaining to the rate of gum exudation (g) in Sterculia urens Roxb during 2015 and 2016 is presented in table 1 and Fig.1. 
The significant variation in rate of gum exudation was observed during March to June. The maximum rate of gum exudation was obtained in month of May in both the experimental years 2015 and 2016 (440.33 and $530.1 \mathrm{~g}$, respectively), followed by April and March. The minimum rate of gum exudation was observed in month of June in both the experimental years.

The rate of gum exudation in Sterculia urens Roxb tree was significantly highest in the month of May and followed by April as compared to March and June during the year 2015 and 2016. It might be due to temperature and relative humidity played a significant role for the process of gummosis and gum exudation. Gum yield was positively related with mean temperature as the temperature increased and relative humidity decreased there was increased in gum yield. The gum yield was significantly higher when tapping was carried out during the sharp decrease of the relative humidity (Harmand et al., 2012). Similar result were also reported by (Bhatt and Mohan Ram, 1990) indicated that 0.8 to $0.9 \mathrm{~kg}$ of good quality gum can be obtained per tree by introducing $4 \mathrm{ml}$ of ethephon containing $960 \mathrm{mg}$ of the active substance through a hole in the sapwood in April/May. It is supported by Harsh et al., (2013).

Amongst the treatments, ethephon @3.9\% $\left(\mathrm{T}_{4}\right)$ was found significantly superior $(717.05$ $\mathrm{g}, 777.45 \mathrm{~g}$ ) followed by @3.12\% ethephon $\left(\mathrm{T}_{3}\right)$ and @2.34\% ethephon $\left(\mathrm{T}_{2}\right)$. The minimum rate of exudation was observed in @IAA 800 ppm ( $\left.\mathrm{T}_{6}\right)(21.43 \mathrm{~g}, 22.789 \mathrm{~g})$ in both the experimental years.

However, control $\left(\mathrm{T}_{1}\right)$ where treated with distilled water produced negligible amount of gum. Gupta et al., (2011) reported that the different doses of ethephon injected in the tree trunk of Sterculia urens by drilling method and $4 \mathrm{ml}$ ethephon, if injected twice, first in mid-March and second in first week of May per tree, further enhances the gum exudation without any apparent ill effect on the health of the tree.

The pooled analysis of effects of chemical tapping in quantity of gum exudation in Sterculia urens Roxb is depicted in table 2.

The quantity of gum was significantly highest in $\mathrm{T}_{4} @ 3.9 \%$ ethephon $(239.02 \mathrm{~g}$ and 259.15 g) followed by $\mathrm{T}_{4} @ 3.12 \%$ ethephon (137.51 $\mathrm{g}$ and $172.36 \mathrm{~g}$ ) and $\mathrm{T}_{2} @ 2.34 \%$ ethephon (66.80 $\mathrm{g}$ and $87.67 \mathrm{~g})$, whereas in $\mathrm{T}_{5} @ 400$ ppm IAA (15.84 $\mathrm{g}$ and $17.30 \mathrm{~g})$ and minimum exudation was obtained in $\mathrm{T}_{6} @ 800$ ppm IAA was obtained maximum gum exudation as compared to treated with @ 800ppm (7.14 g and $7.59 \mathrm{~g}$ ) concentration of IAA. However, in $\mathrm{T}_{1}$ (control, distilled water $4 \mathrm{ml}$ ) no exudation was observed in gum karaya trees.

The pooled average data revealed that the effect of chemical tapping in quantity of gum exudation was significantly obtained highest when treated with @3.9 \% (249.08 g) concentration of ethephon followed by concentration of $3.12 \%(154.93 \mathrm{~g})$ and @2.34 \% (77.23 g). The gum enhancer ethephon treated with concentration of @3.9 $\%$ and @3.12\% produced more gum over control. It may be due to the treatment with ethephon has induced formation of gum ducts and cavities in the stem of Sterculia urens (Babu and Menon 1989). An application of IAA increased number of gum ducts in Sterculia urens (Setia and Shah, 1977a). Sharma and Prasad (2013) also supported that the ethephon application leads sapwood and these results in the clogging of vessels of secondary xylem with gummy material.

\section{Physiochemical analysis of Sterculia urens Roxb}

The $\mathrm{pH}$, solubility and protein content were evaluated and results obtained are summarized in table 3. 
Plate.1 (a) Gum karaya tree (b) Mechanical tapping method (c) Chemical tapping method

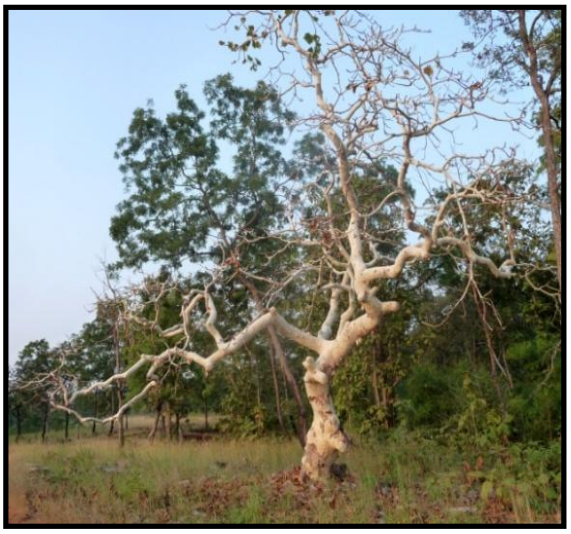

(a)

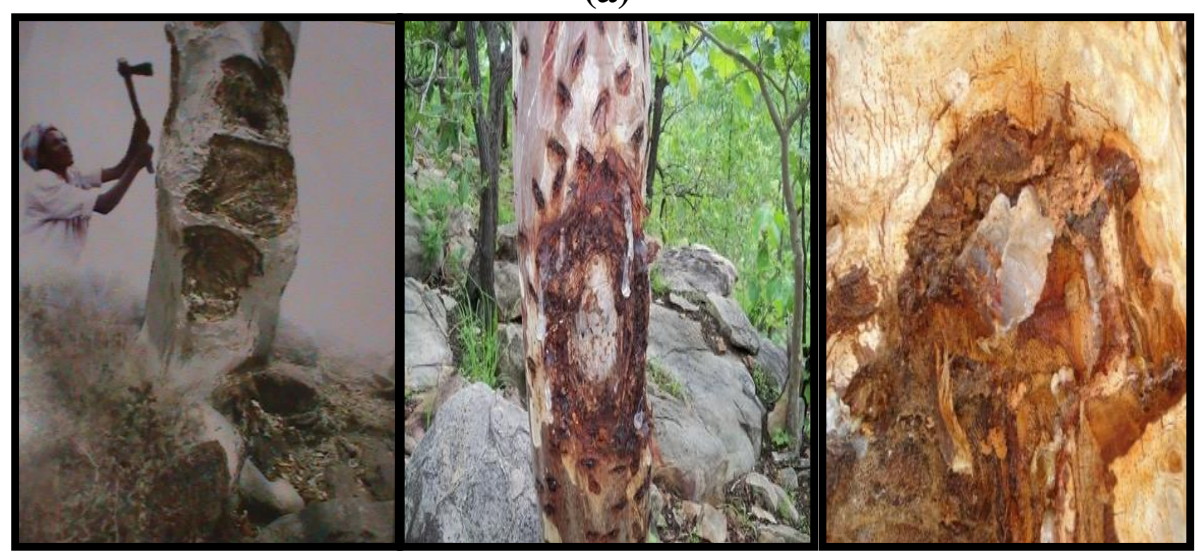

(b)

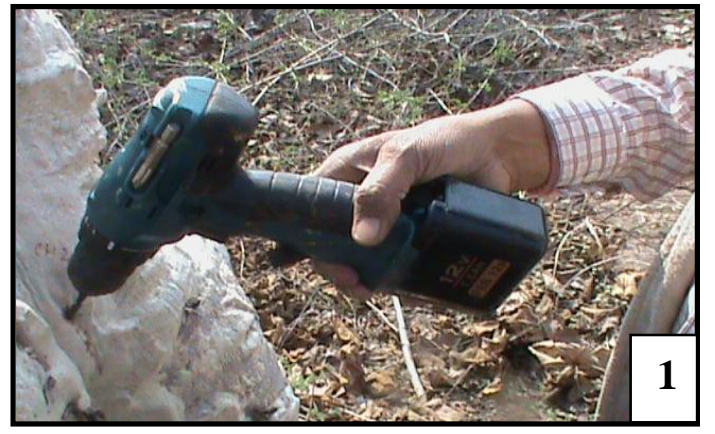

Making hole with battery operated drill

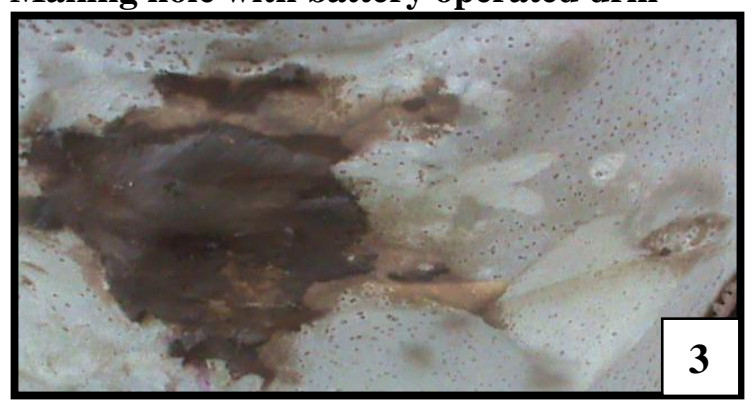

Covering the hole by moistened clay

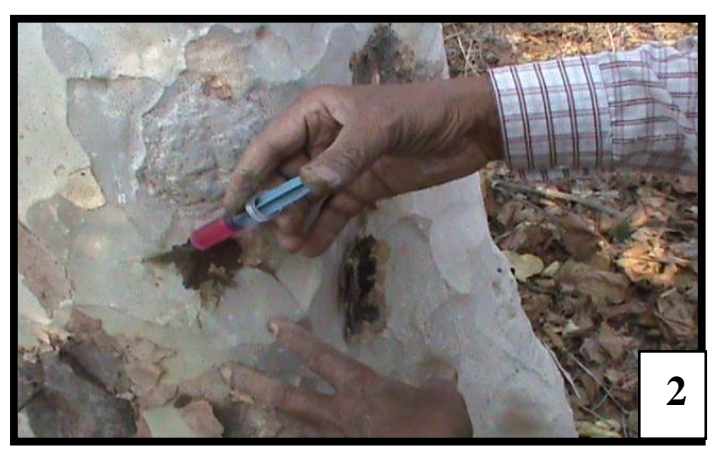

Injected gum inducer ethephon

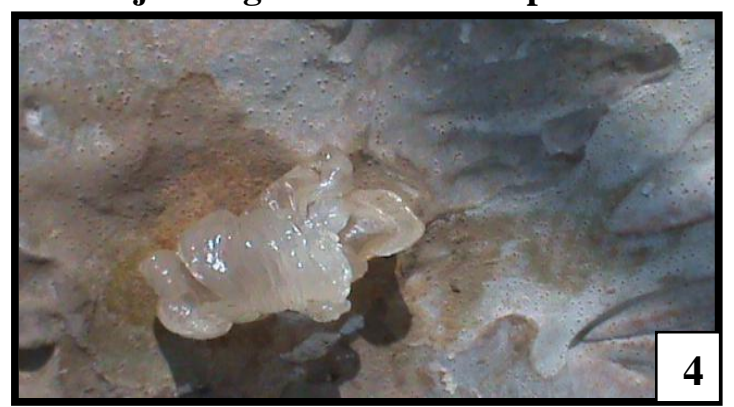

Exudated gum tears

(c) 
Fig.1 Effect of gum inducing chemical ethephon and IAA on rate of gum exudation $(\mathrm{g})$ in Gum karaya (Sterculia urens Roxb) during year 2015 and 2016

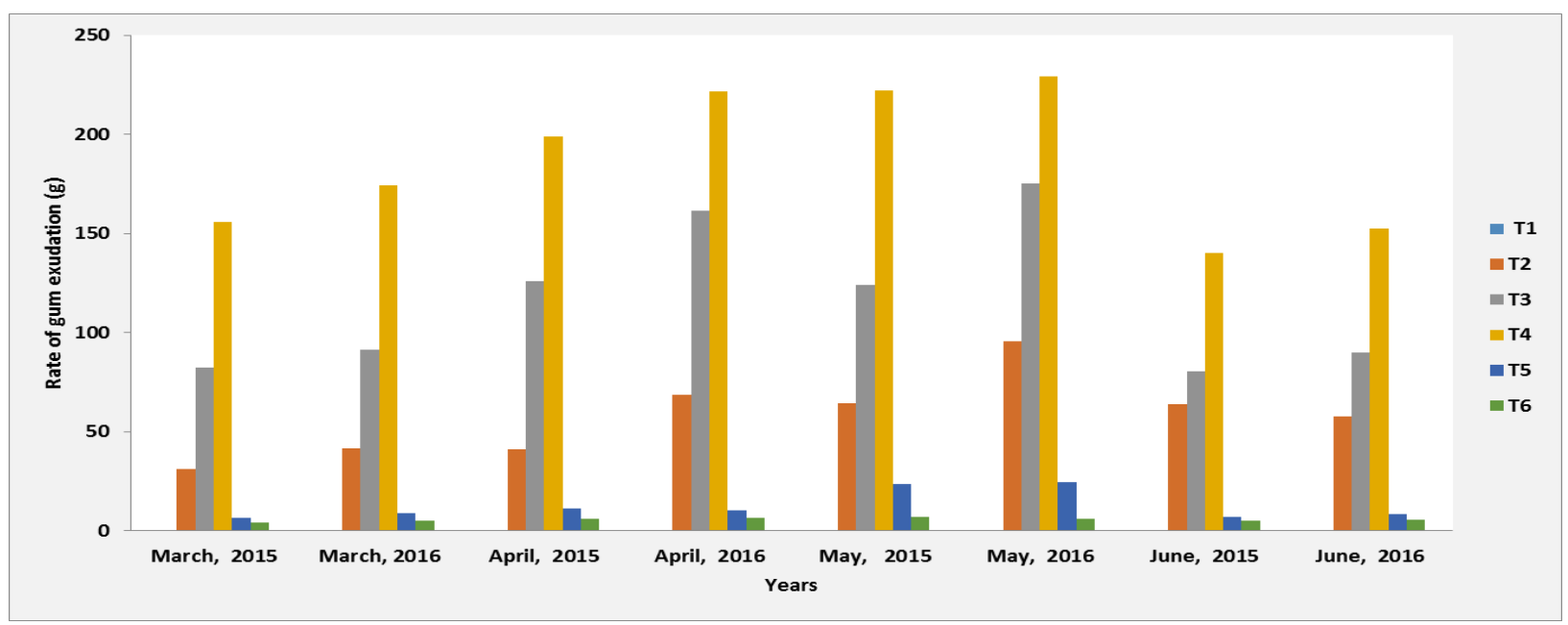

Table.1 Effect of gum inducing chemical ethephon and IAA on rate of gum exudation (g) in Gum karaya (Sterculia urens Roxb) during year 2015 and 2016

\begin{tabular}{|c|c|c|c|c|c|c|c|c|c|c|c|}
\hline \multirow{2}{*}{\multicolumn{2}{|c|}{ Treatments }} & \multicolumn{4}{|c|}{2015} & \multirow[t]{4}{*}{ Total } & \multicolumn{4}{|c|}{2016} & \multirow[t]{4}{*}{ Total } \\
\hline & & March & April & May & June & & March & April & May & June & \\
\hline & Temp. $\left({ }^{0} \mathrm{C}\right)$ & 34.45 & 38.1 & 42.15 & 35.88 & & 35.51 & 38.8 & 42.82 & 37.91 & \\
\hline & RH (\%) & 48.25 & 38.4 & 39.75 & 56.12 & & 51.15 & 37.70 & 35.75 & 57.51 & \\
\hline \multicolumn{2}{|c|}{$T_{1}$ Control (Distilled water) } & 0 & 0 & 0 & 0 & 0 & 0 & 0 & 0 & 0 & 0 \\
\hline \multicolumn{2}{|c|}{$\mathrm{T}_{2}(2.34 \%$ Ethephon $)$} & 31.29 & 41.23 & 64.28 & 63.59 & 200.39 & 41.48 & 68.57 & 95.5 & 57.47 & 263.02 \\
\hline \multicolumn{2}{|c|}{$T_{3}(3.12 \%$ Ehtephon $)$} & 82.46 & 125.88 & 123.87 & 80.33 & 412.54 & 91.29 & 161.26 & 175.18 & 89.9 & 517.63 \\
\hline \multicolumn{2}{|c|}{$\mathbf{T}_{4}(3.9 \%$ Ethephon $)$} & 155.91 & 198.94 & 221.89 & 140.31 & 717.05 & 174.09 & 221.82 & 229.24 & 152.3 & 777.45 \\
\hline \multicolumn{2}{|c|}{$T_{5}(400$ ppm IAA) } & 6.21 & 11.15 & 23.27 & 6.89 & 47.52 & 8.67 & 10.4 & 24.33 & 8.44 & 51.81 \\
\hline \multicolumn{2}{|c|}{$\mathrm{T}_{6}(800 \mathrm{ppm}$ IAA $)$} & 3.81 & 5.81 & 7.02 & 4.79 & 21.43 & 4.97 & 6.42 & 5.85 & 5.54 & 22.78 \\
\hline \multicolumn{2}{|c|}{ Total } & 279.68 & 383.01 & 440.33 & 295.8 & $\mathbf{1 3 9 8 . 9 3}$ & 320.5 & 468.47 & 530.1 & 313.65 & 1632.06 \\
\hline
\end{tabular}

Table.2 Pooled average data of effect of gum inducing chemical ethephon and IAA on quantity of gum exudation ( $\mathrm{g}$ ) in Gum karaya (Sterculia urens Roxb)

\begin{tabular}{lccc}
\hline Treatment & $\mathbf{2 0 1 5}$ & $\mathbf{2 0 1 6}$ & Pooled \\
\hline $\mathbf{T}_{\mathbf{1}}$ Control (Distilled water) & 0 & 0 & 0 \\
$\mathbf{T}_{\mathbf{2}}(\mathbf{2 . 3 4} \%$ Ethephon), & 66.80 & 87.67 & 77.23 \\
$\mathbf{T}_{\mathbf{3}}(\mathbf{3 . 1 2} \%$ Ehtephon) & 137.51 & 172.36 & 154.93 \\
$\mathbf{T}_{\mathbf{4}}(\mathbf{3 . 9 \%}$ Ethephon) & 239.02 & 259.15 & 249.08 \\
$\mathbf{T}_{\mathbf{5}}(\mathbf{4 0 0}$ ppm IAA) & 15.84 & 17.30 & 16.57 \\
$\mathbf{T}_{\mathbf{6}}(\mathbf{8 0 0} \mathbf{p p m}$ IAA) & 7.14 & 7.59 & 7.36 \\
\hline & & & $\mathbf{S E}(\mathbf{m})$ \\
\hline Factors & $\mathbf{C . D}$ & $\mathbf{S E}(\mathbf{d})$ & 4.27 \\
\hline Year & N/A & 6.039 & 7.396 \\
Treatment & 21.832 & 10.46 & 10.46 \\
Interaction year x treatment & N/A & 14.792 & \\
\hline
\end{tabular}


Table.3 Effect of gum inducing chemical ethephon and IAA in physio-chemical properties of Sterculia urens Roxb.

\begin{tabular}{ll}
\hline Parameter & Sterculia urens Roxb. gum \\
\hline $\mathrm{pH}$ & 4.8 \\
\hline Solubility (2\% w/v of solution) & \\
\hline Cold water & $10.66 \%$ \\
\hline Hot water & $31.34 \%$ \\
\hline Acetone & 0 \\
\hline Ethanol & $0.40 \%$ \\
\hline Protein & $1 \%$ \\
\hline
\end{tabular}

The measured $\mathrm{pH}$ of gum is 4.8 , indicating that the gum is mild acetic. This result was agreed with (Taher, 1998).

The solubility of karaya gum in cold water and hot water $10.66 \%$ and $31.34 \%$ respectively, indicating that the solubility of the gum is temperature dependent. The karaya gum least soluble in cold water. The gum particle do not dissolve but absorb water and swell expensively to more than 60 times the original volume, producing a viscous colloidal solution. The swelling behavior of gum karaya is caused by the presence of acetyl groups in its structure (Le Cerf et al., 1990). Since solubility is expected to increase with increase in temperature, the solubility of the gum in hot water is higher than the corresponding solubility in cold water. On the other hand, the samples were not soluble in acetone but sparingly soluble in ethanol.

These indicate that the studied gum is ionic in character unlike the covalent counterpart that is soluble in organic solvents (Sarah et al., 1998). The sparingly solubility of the gum observed in ethanol due to the fact is that it can ionize to produce hydroxyl ion $\left(\mathrm{OH}^{-}\right)$and the value of its dielectric constant is higher than those of acetone. Consequently ethanol has some polar character over acetone which is characterized by low value of dielectric constant. The solubility was also closer to the result obtained by Yadav et al., (2015).
The protein content of karaya gum was found $1 \%$. The most of the gum had very low protein content and was referred to as an arabinogalactan (Hussein et al., 2006).

The future of natural gum industry is uncertain and therefore, a thorough economic study of the national and international trade is necessary. Synthetic products are preferred by the industry because of the uncertain supply and cost of natural gums. However, unstable oil prices, decreased production and high costs of the synthetic material create a promising future for natural gums and resins. In spite of the competition from synthetic products, natural gum and resins are preferred in certain industries as they are superior.

The tapping methods used are brutal and injurious to the plants, often leading to their death. The technology available is old and the innovations are essential for sustainable yield and quality control. A concerted effort by researches and agencies such as research institution, Universities and nongovernmental agencies is urgently needed to improve all aspects of the industry such as tapping, collection, processing, grading, classification and marketing. $\mathrm{R}$ and $\mathrm{D}$ are completely lacking in the area of utilization of natural gums and resins. The industry completely depends on traditional and certain ad hoc investigations by individuals. Research into genetic improvement and selection of 
species for production of gums and resins should be initiated which may lead to establishment of plantation of these species. Gum and resin industry can provide employment and a steady additional income to rural people and thereby stop their migration into the towns and cities.

\section{References}

Ameh, Paul Ocheje, 2012. Physicochemical Properties and Rheological Behavior of Ficus Glumosa Gum in Aqueous Solution. International J. of Modern Chemistry 2(3): 84-99.

Anonymous, 2013. Lac, plant resins and gums statistics at a glance 2012. Indian Institute of Natural Resins and Gums. Indian Council of Agricultural Research, Ranchi- 834 010, Jharkhand.

Babu, A.M., and Menon, A.R.S. 1989. Ethephon induced gummosis in Bombax ceiba L. and Sterculia urens Roxb. Indian Forester, 115(1): 44-47.

Bhatt, J. R., and H.Y. Mohan Ram 1990. Ethephon induced gum production in Acacia senegal and its potential value in the semi-arid regions of India. Current science 59: 1247-1250.

Bhatt, J. R., Nair, M.N.B. and Mohan Ram, H.Y. 1989. Enhancement of oleogumresin production in Commiphora wightii by improved tapping technique. Current Science 58: 349-357.

Bhattacharya, P., 2012. Linking gum harvesting, conservation and livelihoods: a case of participatory management in dry tropical forest of Madhya Pradesh. State Forest Research Institute.

Eddy, Nnabuk O., Ameh, Paul O., Gimba, Casimir E. and Ebenso, Eno E. 2012. Rheological Modeling and Characterization of Ficus platyphylla Gum Exudates. J. of Chemistry. 1-10.

Gupta, R., Patel, S., Katiyar, P. and Modi,
R.K. 2012. Harvesting, processing and value addition of natural resin and gum. Directorate of research services, IGKV, Raipur.

Harmand, J.M., Ntoupka, M., Mathieu, B., Njiti, C.F., Tapsou, J.M., Bois, J.C., Thaler, P. and Peltier, R. 2012. Gum arabic production in Acacia Senegal plantations in the Sudanian zone of Cameroon: Effects of climate, soil, tapping date and tree provenance. BOIS ET FORÊTS DES TROPIQUES, 311(1): 21-33.

Harsh, L.N., Tewari, J.C., Khan, H.A. and Ram, M. 2013. Ethephon-induced gum arabic exudation technique and its sustainability in arid and semi-arid regions of India. Forests, Trees and Livelihoods. 22(3): 204-211.

Hussein, M.S., 2006. Comparative study on some Sudanese gums: Hashab (Acacia senegal), talha (Acacia seyal) and Karaya (Sterculia urens). M.Sc. Thesis, Faculty of science, University of Kordofon.

Le Cerf, D., Irinei, F., and Muller, G. 1990. Solution properties of gum exudates from Sterculia urens (Karaya gum). Carbohydr. Polymer. 13: 375-386.

Rodriguez, G. O.; De Ferrier, B. S.; Ferrier, A.; Rodriguez, B. 2004. Characterization of honey produced in Venezuela, Food Chem., 4: 499-502.

Sao, K.P., 2012. Physico-chemical properties of some Indian plant gums of commercial importance. Indian Institute of Natural Resins and Gums, Indian Council of Agricultural Research, Namkun, Ranchi (Jharkhand). Technical bulletin, 01: 01-64.

Sarah, L.V., Singer, B.W., Hicchen, S.M., Townsend, J.H. 1998. The development and initial application of gas chromatographic method for the characterization of gum media. J. Amer. Inst. Convers.37: 295-311. 
Setia, R. C. and Shah, J.J. 1977a. Effect of Morphactin, IAA and Kinetin on gum canals in Sterculia urens Roxb. Indian Journal of Experimental Biology 15: 297-301.

Setia, Ramesh Chander. 1984. Traumatic duct formation in Sterculia urens Roxb in response to injury. Phyton (Austria), (2): 253-255.

Sharma, S.C., and Prasad, N. 2013. Comparison of gum tapping techniques for gum Karaya - a gum of commercial importance. Journal of Non-Timber Forest Products, 20(3): 165-170.

Simon, S., and Petrasek, J. 2011. Why plants need more than one type of auxin. Plant Science 180 (3): 454-460.
Taher, A.A., 1998. Analytical and structural studies on some plant gum exudates. M.Sc. Thesis, Faculty of science, University of Kordofon.

Yadav, Sandeep, Sharma, K., Pramod and Goyal, K., Narendra. 2015. Comparative Study of mucilage extracted from seeds of Cassia fistula and gum karaya. Advances in Biological Research. 9(3): 177-181.

Yusuf, A. K., 2011. Studies on some physicochemical properties of the plant gum exudates of Acacia senegal (dakwara), acacia sieberiana (farar kaya) and acacia nilotica (bagaruwa). JORIND 9(2): 10-17.

\section{How to cite this article:}

Vidya Bhushan Kuruwanshi, Pratibha Katiyar and Shabnam Khan. 2017. Scientific Approaches of Gum Tapping in Gum Karaya (Sterculia urens Roxb.) for High Gum Production. Int.J.Curr.Microbiol.App.Sci. 6(8): 3366-3374. doi: https://doi.org/10.20546/ijcmas.2017.608.402 